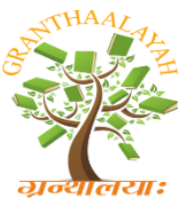

INTERNATIONAL JOURNAL OF RESEARCH GRANTHAALAYAH A knowledge Repository

Social

\title{
EFFECT OF SELECTED YOGIC PRACTICES PHYSICAL EXERCISES AND PHYSIOTHERAPY TREATMENT ON SITTING OF LOW BACK PAIN PATIENTS
}

\author{
Mrs. N.T. Lethi ${ }^{* 1}$, Dr. A.M. Moorthy ${ }^{2}$ \\ ${ }^{* 1}$ Ph.D., Scholar, University of Kerala, India \\ ${ }^{2}$ Vice-Chancellor \& Professor, Tamil Nadu Physical Education and Sports University, Chennai, \\ India
}

DOI: https://doi.org/10.29121/granthaalayah.v5.i4(SE).2017.1950

\begin{abstract}
The purpose of the study was to investigate the effect of selected yogic practices physical exercises and physiotherapy treatment on sitting of low back pain patients. One hundred low back pain patients are taken from the Thavanur town, Kerala. The age, height and weight of the subjects ranged from 30 to 40 years, 158 to 169 centimetres and 55 to 70 kilograms respectively. The selected subjects were randomly assigned into five equal groups of 20 subjects each. Group I underwent Yogic practices, group II underwent physical exercises, group III underwent physiotherapy treatments, group IV yoga and physiotherapy treatments and group V acted as control. Prior to and after the training the subjects were tested on sitting of low back pain patients through the Oswestry low back pain disability questionnaire. Analysis of covariance was used to determine the significantly difference existing between pretest and posttest on sitting of low back pain patients. The result of the study proved that due to twelve weeks of the experimental training was reduced back pain while sitting for the low back pain patients.
\end{abstract}

Keywords: Sitting and Low Back Pain; Yogic Practices; Exercises; Physiotherapy; Treatment.

Cite This Article: Mrs. N.T. Lethi, and Dr. A.M. Moorthy. (2017). "EFFECT OF SELECTED YOGIC PRACTICES PHYSICAL EXERCISES AND PHYSIOTHERAPY TREATMENT ON SITTING OF LOW BACK PAIN PATIENTS." International Journal of Research - Granthaalayah, 5(4)SE, 63-68. https://doi.org/10.29121/granthaalayah.v5.i4(SE).2017.1950.

\section{Introduction}

The series of yoga poses called asana work by safely stretching our muscles. This releases the lactic acid that builds up with muscle use and causes stiffness, tension, pain, and fatigue. In addition, yoga increases the range of motion in joints. It may also increase lubrication in the joints. The outcome is a sense of ease and fluidity throughout our body. The yoga exercises are help to give the relief from the back pain and good prevention from muscles problems also 
rectify for the spinal disorders for the good posture. These yoga exercises are help the individuals to be a good physical posture and strengthen their back muscles, abdominal, lower body and neck muscles.

Chronic low back pain is associated with sleep problems, including a greater amount of time needed to fall asleep, disturbances during sleep, a shorter duration of sleep, and less satisfaction with sleep (Kelly and others, 2011). Exercise appears to be useful for preventing low back pain (Steffens and others, 2016). Exercise is also probably effective in preventing recurrences in those with pain that has lasted more than six weeks.

\section{Methodology}

\subsection{Subjects and Variables}

The purpose of the study was to investigate the effect of selected yogic practices physical exercises and physiotherapy treatment on sitting of low back pain patients. One hundred low back pain patients are taken from the Thavanur town, Kerala. The age, height and weight of the subjects ranged from 30 to 40 years, 158 to 169 centimetres and 55 to 70 kilograms respectively. The selected subjects were randomly assigned into five equal groups of 20 subjects each. Group I underwent Yogic practices, group II underwent physical exercises, group III underwent physiotherapy treatments, group IV yoga and physiotherapy treatments and group V acted as control. Prior to and after the training the subjects were tested on sitting of low back pain patients through the Oswestry low back pain disability questionnaire. Analysis of covariance was used to determine the significantly difference existing between pretest and posttest on sitting of low back pain patients.

\subsection{Training Protocol}

The Group I performed Yogic practices three sessions per week on alternative days for 12 weeks and each session lasted from 20 to 40 minutes. The following yoga was performed Naukasana, Dhanurasana, Bhujangasana, Uttanapadasana, Salabhasana, Janusirasana, Pavanamukthasana and Yog Mudra. The recovery period between asana was fifteen seconds and between sets one minute. The sets and repetition was increased in progress. Group II underwent physical exercises programme three sessions per week on alternative days for 12 weeks and each session lasted from 20 to 40 minutes. The recovery period between exercises was sixty seconds and between sets three minutes. The following physical exercises are performed by the subjects straight leg race, single knee to chest stretch, hamstring stretch, hip flexes stretch, lower trunk rotation stretch, prone lumber extension and pelvic filt. Group III underwent physiotherapy treatments for 12 weeks. The following physiotherapy treatments are given to the subjects. 10 min ice therapy, hot moist packs, ultra sound therapy, short wave diathermy, infra-red radiation and wax bath. Group IV underwent the yoga practice and physiotherapy treatments for twelve weeks. Group V acted as control. 


\subsection{Experimental Design and Statistical Technique}

The experimental design used in this study was random group design involving 100 subjects, who were divided at random in to five groups of twenty each. All the five groups were selected from the same population. The data collected from the five groups prior to and post experimentation on sitting was statistically analyzed to find out the significant difference if any, by applying the analysis of covariance (ANCOVA). Since five groups were involved, whenever the obtained ' $F$ ' ratio for adjusted posttest means was found to be significant, the Scheffe's test was applied as post hoc test to determine the paired mean differences. In all the cases level of confidence was fixed at 0.05 for significance.

\section{Results}

\section{Sitting}

The pre and post test data collected from the experimental and control groups on sitting of low back pain patients were statistically analysed by ANCOVA and the results are presented in table1.

Table 1: Analysis of Covariance on Sitting of Experimental and Control Groups

\begin{tabular}{|c|c|c|c|c|c|c|c|c|c|c|}
\hline & 异 & 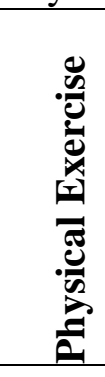 & 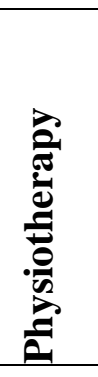 & 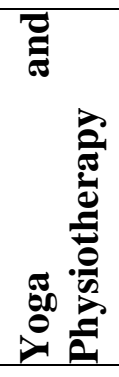 & 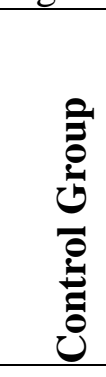 & $\begin{array}{l}\mathbf{S} \\
\mathbf{O} \\
\mathbf{V}\end{array}$ & 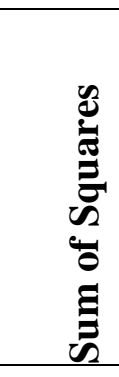 & df & 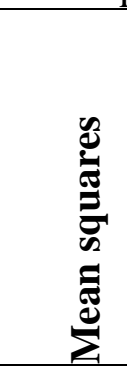 & 赵 \\
\hline \multirow{2}{*}{$\begin{array}{l}\text { Pre test } \\
\text { Mean } \\
\text { SD }\end{array}$} & 4.25 & 4.35 & 4.15 & 4.45 & 4.70 & B & 3.56 & 4 & 0.89 & \multirow{2}{*}{1.05} \\
\hline & 1.01 & 1.18 & 0.98 & 0.68 & 0.57 & W & 80.01 & 95 & 0.84 & \\
\hline \multirow{2}{*}{$\begin{array}{l}\text { Post test } \\
\text { Mean } \\
\text { SD }\end{array}$} & 3.80 & 3.45 & 3.65 & 3.10 & 4.80 & B & 32.54 & 4 & 8.13 & \multirow{2}{*}{$13.87 *$} \\
\hline & 0.83 & 0.75 & 0.81 & 0.91 & 0.41 & W & 55.70 & 95 & 0.58 & \\
\hline \multirow{2}{*}{$\begin{array}{l}\text { Adjusted } \\
\text { Post test } \\
\text { Mean }\end{array}$} & \multirow{2}{*}{3.82} & \multirow{2}{*}{3.45} & \multirow{2}{*}{3.69} & \multirow{2}{*}{3.08} & \multirow{2}{*}{4.73} & B & 29.67 & 4 & 7.41 & \multirow{2}{*}{$13.36^{*}$} \\
\hline & & & & & & W & 52.17 & 94 & 0.55 & \\
\hline
\end{tabular}

(The required table value for significance at 0.05 level of confidence with degrees of freedom 4 and 95 is 2.47 and degree of freedom 4 and 94 is 2.47)

*Significant at .05 level of confidence

The adjusted post test means on sitting of low back pain patients of yoga practice, physical exercise, physiotherapy, yoga and physiotherapy and control groups are 3.82, 3.45, 3.69, 3.08 and 13.36 respectively. The obtained ' $F$ ' ratio value of 11.35 for adjusted post test means on sitting of low back pain patients of yoga practice, physical exercise, physiotherapy treatment, 
yoga and physiotherapy treatments and control groups were higher than the required table value of 2.47 for the degrees of freedom 4 and 94 at 0.05 level of confidence. It reveals that there is statistically significant difference among the yoga practice, physical exercise, physiotherapy treatment, yoga and physiotherapy treatments and control groups during adjusted post test period on sitting.

Since, the adjusted posttest ' $F$ ' ratio value is found to be significant the Scheffe's test is applied as post hoc test to determine the paired mean differences, and it is presented in table-II.

Table 2: Scheffe's Test for the Difference between the Adjusted Post Test Paired Means of Sitting

\begin{tabular}{|c|c|c|c|c|c|c|}
\hline \multicolumn{5}{|c|}{ Adjusted Post Test Means } & \multirow[b]{2}{*}{ DM } & \multirow[b]{2}{*}{ CI } \\
\hline 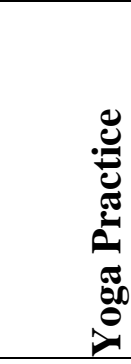 & 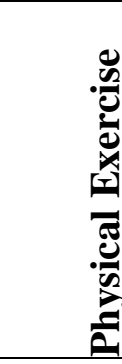 & 递 & 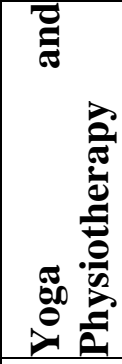 & $\begin{array}{l}\text { Control } \\
\text { Group }\end{array}$ & & \\
\hline 3.82 & 3.45 & & & & 0.37 & 0.52 \\
\hline 3.82 & & 3.69 & & & 0.13 & 0.52 \\
\hline 3.82 & & & 3.08 & & $0.74^{*}$ & 0.52 \\
\hline \multirow[t]{7}{*}{3.82} & & & & 4.73 & $0.91 *$ & 0.52 \\
\hline & 3.45 & 3.69 & & & 0.24 & 0.52 \\
\hline & 3.45 & & 3.08 & & 0.37 & 0.52 \\
\hline & 3.45 & & & 4.73 & $1.28^{*}$ & 0.52 \\
\hline & & 3.69 & 3.08 & & $0.61 *$ & 0.52 \\
\hline & & 3.69 & & 4.73 & $1.04^{*}$ & 0.52 \\
\hline & & & 3.08 & 4.73 & $1.65^{*}$ & 0.52 \\
\hline
\end{tabular}

*significant

Table-II shows the Scheffe's test results that there is significant difference exists between the adjusted posttests means of yoga practice and yoga \& physiotherapy treatments groups; yoga practice and control groups; physical exercise and control groups; physiotherapy and yoga \& physiotherapy treatments group; physiotherapy and control groups; yoga \& physiotherapy and control groups on sitting of low back pain patients. And also there is no significant difference exists between yoga practice and physical exercise; yoga practice and physiotherapy groups; physical exercise and physiotherapy groups; physical exercise and yoga \& physiotherapy groups. The conclusion of the study stated that yoga \& physiotherapy treatment is better influenced to reduce the low back pain while sitting for the subjects when compared to other experimental groups. 


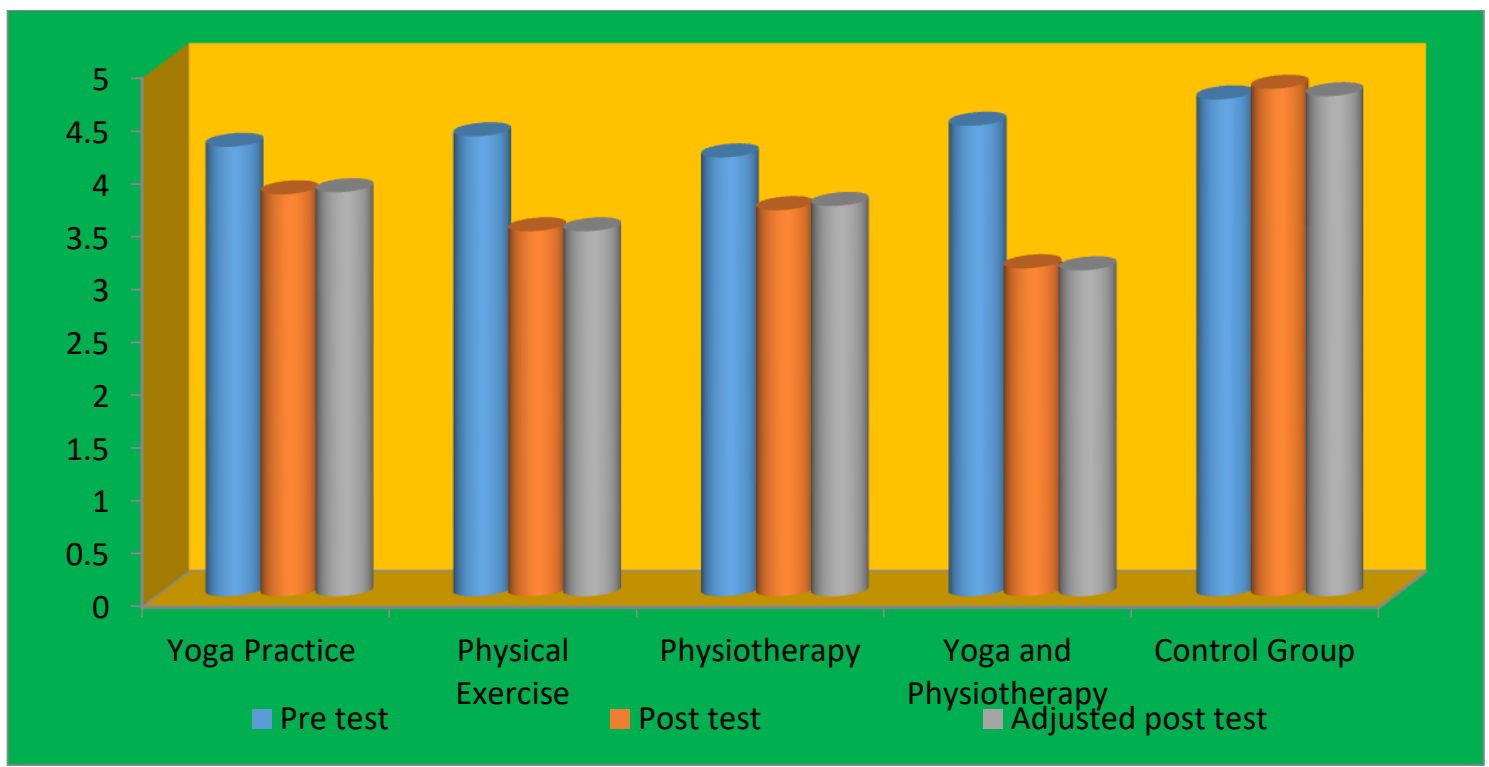

Figure 1: Cylinder Diagram Showing the Mean Value on Sitting of Experimental and Control Groups

\section{Discussion and Conclusions}

The result of the study showed that yoga practice, physical exercise, physiotherapy treatments, yoga \& physiotherapy treatments and control groups had significant difference on sitting of low back pain patients. However yoga \& physiotherapy treatment is better influenced to reduce the low back pain while sitting for the subjects when compared to other experimental groups. The following studies are supporting with my study results. Ravi and Karuna (2012) evaluated the effect of conventional occupational therapy and yoga in chronic low back Pain. The study stated that yoga can be effectively used as an adjunctive method with conventional occupational therapy in patients with chronic low back pain for a sound mental and physical health. Sherman (2010) examined the comparison of yoga versus stretching for chronic low back pain. This study concluded that the clearest evidence to date about the value of yoga as a therapeutic option for treating chronic back pain, and if the results are positive.

\subsection{Conclusion}

The conclusion of the study stated that yoga \& physiotherapy treatment are influenced to reduce the low back pain while sitting of the subjects.

\section{References}

[1] Chrysolyte, S. V., \& Raja, B. W. D. ATTITUDE OF PLUS TWO STUDENTS TOWARDS PUBLIC EXAMINATION IN RELATION TO PARENTAL PRESSURE.

[2] Golden, S. A. R. (2011). Strategy For Success Of Human Beings:-Time Management.

[3] Golden, S. A. R. (2017). Recent Research In Social Science \& Humanities.

[4] Kelly, G.A., Blake, C., Power, C.K., O'keeffe, D., Fullen, B.M., (2011). The association between chronic low back pain and sleep: a systematic review. Clin J Pain. 27(2): 169-81. 
[5] Ravi Wattamwar, B., and Karuna Nadkarni., (2012). Effect of conventional occupational therapy and yoga in chronic low back Pain. The Indian Journal of Occupational Therapy. 45 (2): 13-20.

[6] Sherman Karen, J., Cherkin Daniel, C., Cook Andrea, J., Hawkes Rene, J., Deyo Richard, A., Robert Wellman and Khalsa Partap, S., (2010). Comparison of yoga versus stretching for chronic low back pain. BioMed Central. 11 (36).

[7] Steffens Daniel., Maher Chris, G., Pereira Leani, S. M., Stevens Matthew, L., Oliveira Vinicius, C., Chapple Meredith,. Teixeira-Salmela Luci, F., Hancock Mark, J., (2016). Prevention of Low Back Pain. JAMA Internal Medicine. 176: 199-208. 